\title{
CDISC SDTM Microscopic Findings Test Name Terminology
}

National Cancer Institute

\section{Source}

National Cancer Institute. CDISC SDTM Microscopic Findings Test Name Terminology. NCI Thesaurus. Code C132262.

Terminology associated with the SDT M microscopic findings test name codelist of the Clinical Data Interchange Standards Consortium (CDISC) Study Data Tabulation Model (SDTM). 